\title{
Reflections on Errors in Neonatology: I. The "Hands-Off" Years, 1920 to 1950
}

\author{
Alex F. Robertson, MD
}

This series discusses errors in neonatology since the 1920s. Three historical periods are defined: the "Hands-Off" years, 1920 to 1950; the "Heroic" years, 1950 to 1970; and the "Experienced" years, 1970 to 2000. In this article, the "Hands-Off" years, we discuss lowered thermal environment, supplemental oxygen, initial thirsting and starving, synthetic vitamin $\mathrm{K}$, SMA formula, and diaper markings.

Journal of Perinatology (2003) 23, 48-55 doi: 10.1038/sj.jp.7210842

\section{INTRODUCTION}

In any rapidly changing medical field, treatments and procedures may be instituted without controlled outcome measurement that might reveal untoward effects. This lack of controlled measurements has certainly been true in neonatology. A classic example is using high oxygen concentrations in caring for premature infants, resulting in retrolental fibroplasia (RLF). Silverman, ${ }^{1}$ in his 1980 book Retrolental Fibroplasia: A Modern Parable, discusses examples of therapies that led to "disasters"

(Chapter 10, Medical Inflation). But many colleagues still surprise me by not being more cautious about new therapies. And I worry also about the safety of currently accepted, but untested, therapies that I have used.

Stories about the mistakes in neonatology are both educational and fascinating, reminiscent of the wonderful medical detective stories of Berton Roueché. Indeed, one of his stories tells of an epidemic of Pseudomonas infection in premature infants that resulted from contamination of delivery room resuscitation equipment at Magee-Women's Hospital in Pittsburgh. ${ }^{2}$

I use the word error to indicate an act that unintentionally deviates from what is correct. But that does not mean the errors were unavoidable. It is interesting that most of the errors relate to

Department of Pediatrics, Brody School of Medicine, East Carolina University, Greenville, NC, USA.

Address correspondence and reprint requests to Alex F. Robertson, MD, Department of Pediatrics, Brody School of Medicine, East Carolina University, 600 Moye Boulevard, Greenville, NC 27858 - 4354, USA. historical developments in medicine and might not have happened in another era. For example, the formula-induced pyridoxine deficiency seizures, discussed later, occurred before infants' pyridoxine requirement was known. Therefore, I will present these cautionary tales in a historical and, occasionally, personal setting with appropriate references for further details. I have excluded problems arising from maternal medications (most notably the diethylstilbestrol disaster) and also excluded medication errors related to using the wrong agent. I have avoided most instances where there seems to be uncertainty about an effect. I have included changes in procedures, which demonstrate that every change in hospital procedures should involve a consideration of the effect on neonatal patients. I have emphasized more recent events and attempted to establish a time frame for the events.

The errors are grouped in three time periods related to the historical setting of neonatology. The first period, from 1920 to 1950, is the "Hands-Off" years. In an address titled, "Neonatal Pediatrics at the Century Mark", Silverman ${ }^{3}$ describes the "hands-off" attitude. "In a previously stable 'weakling,' bouts of apnea, cyanosis, and deterioration of vitality seemed to be triggered by handling during routine procedures. The observations led to a dogmatic 'hands-off' policy of care. .." Infant care was a nursing task comprised primarily of warming, feeding, and isolation. This attitude began changing in the 1940s with the obvious success of exchange transfusions for erythroblastosis fetalis, and the advent of antibiotics in the 1950s. The realization that RLF was an iatrogenic disease spawned research in oxygen monitoring and aided in the development of infant ventilators in the 1960s. Silverman ${ }^{1}$ refers to this period as one of "therapeutic exuberance" (p. 75). We will call this period, from 1950 to 1970, the "Heroic" years.

Pediatricians now entered the nursery and there was a "great spirit of innovation, somewhat lacking in discipline" (Baker, personal communication). This is the period of the most striking care changes and errors. From 1970 on will be called the "Experienced" years, during which neonatal practice becomes a bit more uniform with refinement of many of the new methods introduced in the "Heroic" years. Fewer errors are apparent, perhaps because of lessons learned, the introduction of randomized controlled studies, or, simply, failure to recognize adverse results in our complex system of care.

Table 1 lists the errors to be discussed, the results, and the years involved. This first article considers the errors that occurred 


\begin{tabular}{|llc|}
\hline Table 1 Errors in Neonatology & \\
\hline Event & \multicolumn{1}{|c|}{ Result } & Years \\
\hline I. The "Hands-Off" years & & \\
Lowered thermal environment & increased mortality & $1900-1964$ \\
Supplemental oxygen & RLF & $1941-1954$ \\
Initial thirsting and starving & ? neurological deficits & $\sim 1945-1970$ \\
Synthetic vitamin K & kernicterus & $1945-1961$ \\
SMA formula & seizures & $1951-? 1952$ \\
Diaper markings & methemoglobinemia & $1886-1995$ \\
& & \\
II. The "Heroic" years & & \\
Bloxsom Air-Lock & ? delayed resuscitation & $1950-1956$ \\
Sulfisoxazole & kernicterus & $1953-1956$ \\
Chloramphenicol & "gray baby" syndrome & $1956-1960$ \\
Novobiocin & jaundice & $1957-1962$ \\
Hexachlorophene & brain lesions & $1952-1971$ \\
Epsom salts enemas & magnesium intoxication & $1964-1965$ \\
Feeding gastrostomy & increased mortality & $1963-1969$ \\
Diaper laundering & "sweating" syndrome & 1969 \\
Equipment cleaning & jaundice & $1972-1975$ \\
& & \\
III. The "Experienced" years & & $1969-1983$ \\
Neo-Mul-Soy formula & metabolic alkalosis & $1978-1979$ \\
Premature infant formulas & lactobezoars & $1977-1980$ \\
Erythromycin & pyloric stenosis & $1976-1999$ \\
Propylene glycol & hyperosmolality, seizures & $1981-1982$ \\
Benzyl alcohol & "gasping" syndrome & $? 2 ? 84$ \\
Intravenous vitamin E & multiorgan damage & $1983-1984$ \\
Steroids & ? cerebral palsy & $1985-2001$ \\
\hline
\end{tabular}

during to the "Hands-Off" years. Many of these errors arose from a lack of knowledge of newborn physiology and the acceptance of authoritarian opinions.

\section{LOWERED THERMAL ENVIRONMENT}

Although mothers have always known intuitively that newborn infants should be kept warm, the importance of this environmental factor was documented when it was shown in the early 1800s that neonatal mortality was greater during France's cold months. The exposure to cold was attributed to the French law that parents must register their newborn infant at the mayor's office shortly after birth (Ref. [4], p. 16). The newborn infant's susceptibility to cold was especially true in premature infants. Although varied methods of warming infants had been used for centuries, the first incubator was probably developed around 1835 in St. Petersburg, Russia. The first report of an incubator used in the care of premature infants was published by Denucé in 1857. In 1884, Credé described his results using a similar incubator in Leipzig over the previous 20 years. ${ }^{5}$ In 1880, the Tarnier incubator, which could be closed, was developed in Paris. The Tarnier incubator was reported to decrease the mortality of infants weighing less than $2000 \mathrm{~g}$ from $66 \%$ to $38 \%$. In the 1890 s, the Lion incubator was developed, which was more sophisticated and was subsequently used in many of the incubator baby shows. ${ }^{6}$ Subsequent incubator development is described by Hess ${ }^{7}$ in his text, Premature and Congenitally Diseased Infants, published in 1922 (Chapter IX, Incubators) and by Baker ${ }^{4}$ in his book, The Machine in the Nursery.

As overheating in these early incubators was a common problem and because the temperature requirement for thermal stability in premature infants decreases with postnatal age, lower temperatures were thought safer. Budin, ${ }^{8}$ the French obstetrician and author of the influential textbook, The Nursling, describing his procedures at the Maternité hospital in Paris around 1900 - heating the Tarnier incubators to $25^{\circ} \mathrm{C}\left(77^{\circ} \mathrm{F}\right)$ (p. 14). Baker ${ }^{4}$ suggests that this decision was based partly on Budin's experience with larger and older babies that came to their hospitals (pp. 61-62).

The first large-scale testing of environmental conditions was in Boston by Blackfan and Yaglou. ${ }^{9}$ They were interested in finding the best conditions of temperature, humidity, and air flow rate for stabilizing the body temperature of newborn infants. Climate control rooms ("conditioned nurseries") were built in order to systematically vary the temperature and humidity. They recognized the difficulties of temperature control in premature infants and that these infants needed additional heat to achieve an acceptable body temperature.

They first studied body temperature response to environmental temperatures between 77 and $100{ }^{\circ} \mathrm{F}\left(25-37.8^{\circ} \mathrm{C}\right)$ over 3.5 hours. The higher temperatures led to overheating, especially in the smaller premature infants. Therefore, they focused on the temperature range where body temperature stability was reached, not realizing that a stable (but subnormal) temperature could still be a physiologic stress. Subsequently, they treated smaller premature infants $(681-1589 \mathrm{~g})$ in a room temperature of 80 to $87^{\circ} \mathrm{F}\left(27-30{ }^{\circ} \mathrm{C}\right)$ and larger premature infants (1589-2497 g) in a room temperature of $77^{\circ} \mathrm{F}\left(25^{\circ} \mathrm{C}\right)$. They then compared the mortality figures of infants cared for in the "conditioned nurseries" to that of infants cared for over previous years in the "unconditioned nurseries." They found that babies in the "conditioned nurseries" had more stable temperatures and a lower mortality, but found no relation of mortality to the specific body temperature (probably all subnormal) where stabilization occurred. This finding of no mortality difference is probably explained by the age and weight of the premature infants admitted to their unit. The majority of the infants in the mortality study were over 15 days old and over $3.4 \mathrm{lb}$ on admission. Also, infants who died within 48 hours of admission were excluded. These authors, like Budin, really had little experience with small premature infants in the first hours of life.

The authors concluded, "The predisposition to a subnormal temperature, particularly in infants of the low weight group, is believed to be a characteristic of prematurity which should be preserved. Attempts to force the body temperature of small infants to 
the supposedly normal level of $98.6^{\circ} \mathrm{F}$ should be discouraged, as in a number of instances such a practice has been followed by overheating with its resultant serious consequences." This report in 1933 thus perpetuated the error of inappropriate thermal environment.

The subsequent history of developing an appropriate thermal environment is described by Silverman ${ }^{10}$ who, in 1954 , began a trial comparing mortality at varying levels of humidity. This interest arose from the "widely and uncritically adopted" use of higher humidities for infants with respiratory distress. Mortality was lower in the higher humidity, and Dr Silverman later explained this result as due to less evaporative heat loss by the infants in high humidity, thereby leading to the maintenance of a higher body temperature. Subsequent studies showed a lower mortality at higher ambient temperatures. Table 2 presents the results reported by Silverman ${ }^{11}$ comparing incubator temperatures of $29^{\circ} \mathrm{C}\left(84^{\circ} \mathrm{F}\right)$ ("hypothermic") to $32{ }^{\circ} \mathrm{C}$ $\left(90{ }^{\circ} \mathrm{F}\right)$ ("normothermic"). The survival rate, especially in the infants below $1001 \mathrm{~g}$, is markedly lower in the "hypothermic" incubators.

This research began the development of servo-controlled incubators. Realization of the importance of higher environmental temperatures led to the concept of a "neutral thermal environment," which is the environmental temperature at which an individual infant can maintain a normal central temperature without physiologic changes. This concept led to the clarification of appropriate incubator temperature settings. It is impossible to know how many babies died from inappropriate environmental temperature during the approximately 50 years before newborn temperature control physiology was understood.

\section{SUPPLEMENTAL OXYGEN}

In 1772, Karl Wilhelm Scheele, an apprentice to an apothecary in Göteborg, Sweden, first isolated oxygen. However, Joseph Priestley in England was the first to publish his experiments in 1775 and gained most credit for the discovery. In a 1790 publication, Priestley described breathing the "dephlogisticated air," as he called it, and said that his "breast felt particularly light and easy." He also predicted its future medical use saying, "...from the greater strength and vivacity of the flame of a candle, in this pure air, it may be conjectured, that it might be peculiarly salutary to the lungs in certain morbid cases..." Both Scheele and Priestly incorrectly described the new gas as lacking in phlogiston. Lavoisier in France corrected this error and coined the term oxygène. $^{12}$

In 1900, Budin ${ }^{8}$ recommended the use of oxygen for premature infants during episodes of cyanosis (p. 23). In 1923, Bakwin noted that oxygen administration not only relieved cyanosis but also diminished the number of subsequent cyanotic episodes. He recommended extended periods of oxygen administration. ${ }^{13}$ The use of oxygen in babies with apnea, cyanosis, and perinatal asphyxia was also promoted by Hess ${ }^{14}$ at the Sarah Morris Premature Infant Station in Chicago where an oxygen therapy unit was devised by replacing the canopy of the Hess-heated bed (incubator) with an oxygen delivery system in 1931. In this incubator, even acyanotic premature infants received $\sim 40 \%$ oxygen for 24 or more hours. In 1938, Chapple ${ }^{15}$ described an incubator that circulated outdoor air through the incubator, maintained a positive pressure air flow to prevent nursery air entering the incubator, and had porthole access with balloon sleeves (Figure 1). Later, Chapple further improved the design using molded plastics developed during the Second World War. Incubators were now air-tight and the infants somewhat isolated from harmful bacteria. Air-Shields subsequently manufactured this incubator. In these incubators, it was difficult to achieve a high oxygen concentration because the oxygen flow was diluted with the flow of outside air. The company changed the design of the inflow port, enabling higher oxygen concentrations inside (Ref. [1], Chapter 7, Oxygen Treatment Practices in Premature Infant Care).

In 1942, Wilson et al. ${ }^{16}$ reported that premature infants breathed with a more regular pattern if they were nursed in 70\% oxygen. Dr. Wilson was the Chairman of Pediatrics at the University of Michigan in 1957 when I arrived as a pediatric intern. His training was in Boston, under Dr Blackfan, mentioned earlier. Every weekday morning, he presided at a case conference with the residents and many of the faculty members. For 4 years of my stay there, I was influenced by and enjoyed his persistent cynicism. As he required such rigorous logic in our approach to patients, I later wondered how a paper he had written might have led to a harmful treatment that he certainly would have

Table 2 Survival Rates by Birth Weight at Two Conditions of Ambient Temperature $80 \%$ to $90 \% \mathrm{RH}$

\begin{tabular}{|c|c|c|c|}
\hline & $\begin{array}{l}\text { "Normothermic" incubator } \\
\text { [(number) survival rate] }\end{array}$ & $\begin{array}{l}\text { "Hypothermic" incubator } \\
\text { [(number) survival rate }]\end{array}$ & $\begin{array}{l}\text { Difference } \\
(\%)\end{array}$ \\
\hline Entire series & ) $84 \%$ & (91) 68\% & 16 \\
\hline \multicolumn{4}{|l|}{ Birth weight $(\mathrm{g})$} \\
\hline Above 1500 & (42) $93 \%$ & (42) $79 \%$ & 14 \\
\hline $1001-1500$ & (35) $86 \%$ & (35) $77 \%$ & 9 \\
\hline Below 1001 & (14) $50 \%$ & (14) $14 \%$ & 36 \\
\hline
\end{tabular}




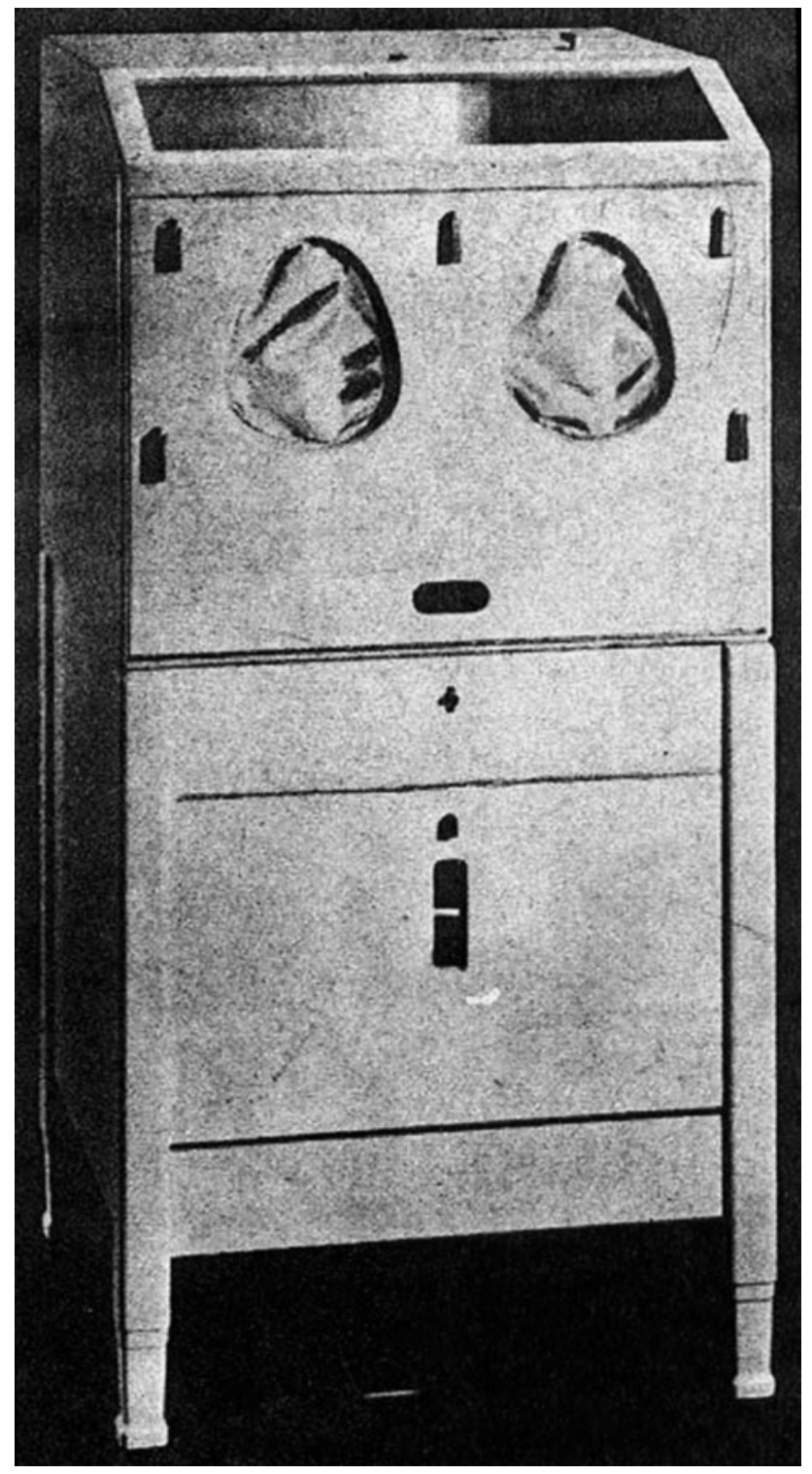

Figure 1. The Chapple incubator.

questioned at our morning meetings. The exact phrasing is interesting:

We bave no proof that the regular type of respiration, which we are accustomed to consider "normal," is better for a premature infant than the periodic type of breathing described. Likewise, we have no convincing evidence that an increased oxygen content of arterial blood is beneficial or necessarily of importance. It is evident, however, that these healthy premature infants breathed in a more normal manner in an oxygen-enriched atmosphere.

Dr Wilson showed that 70\% oxygen prevented 'periodic breathing,' the normal alteration in rate and amplitude of breathing in premature infants. Periodic breathing was concerning since, at that time, some physicians felt that periodic breathing resulted from unapparent hypoxemia. Dr Wilson apparently agreed, stating, "Any effect from the administration of oxygen, therefore, establishes that the preceding alveoli oxygen content has not been normal or that abnormal conditions of gas diffusion in the lung exist.'

These changes in incubator design and the interest in avoiding periodic breathing and apneic and cyanotic episodes led to the use of higher concentrations of oxygen in many premature infants. And there was little criticism or worry about this treatment. For example, in 1950, Smith ${ }^{17}$ stated, "We use a great deal of oxygen in our two premature infant nurseries, as everyone else does. In our own experience, we have never altered this factor without at the same time introducing other changes in our methods. Nor have we ever treated alternate patients with and without oxygen, and I rather hope we never shall."

RLF was first recognized in 1940 by Dr Stewart H. Clifford, a Boston pediatrician, and was subsequently carefully studied by Dr Theodore Terry, an ophthalmologist. By 1950, RLF was recognized as the principal cause of blindness in infants. By 1953, approximately 10,000 children were blind due to the disease. An interesting sidelight to this story is told by Silverman ${ }^{18}$ concerning the use of ACTH as therapy in a series of his patients. Early results were encouraging and pressure to publish the uncontrolled results mounted. However, a controlled trial was designed, carried out, and showed no beneficial results. This study was the first randomized controlled trial in newborn infants.

In 1951, the question as to whether oxygen toxicity was the cause of RLF began to surface. This idea apparently was suggested by Crosse and Evans in England and reported by Campbell in Australia (Ref. [1], p. 25). In July 1953, 18 hospitals in the US began a collaborative study comparing unrestricted and restricted oxygen therapy in infants weighing less than $1500 \mathrm{~g}$ at birth. As many pediatricians, by then, suspected that oxygen was a causative factor, the study was designed so that only $1 / 12$ of the infants would be assigned to the unrestricted oxygen group. In September 1954, the preliminary results were presented (Table 3) (Ref. [1], p. 41). This table shows that both nonscarring and scarring RLF were less frequent in the restricted oxygen groups.

Table 3 Frequency of RLF in the Cooperative Study, by Multiplicity of Birth and Severity of RLF (July 1, 1953-June 30, 1954)

\begin{tabular}{|c|c|c|c|c|c|}
\hline \multirow[t]{2}{*}{ Oxygen group } & \multirow[t]{2}{*}{$\begin{array}{l}\text { Number of } \\
\text { infants }\end{array}$} & \multicolumn{2}{|c|}{$\begin{array}{l}\text { Blood vessel } \\
\text { changes of RLF }\end{array}$} & \multicolumn{2}{|c|}{ Scarring RLF } \\
\hline & & Number & $\%$ & Number & $\%$ \\
\hline \multicolumn{6}{|l|}{ Singleton } \\
\hline Routine oxygen & 47 & 33 & 70 & 8 & 17 \\
\hline Curtailed oxygen & 425 & 133 & 31 & 20 & 5 \\
\hline \multicolumn{6}{|l|}{ Multiple birth } \\
\hline Routine Oxygen & 6 & 5 & 83 & 4 & 67 \\
\hline Curtailed oxygen & 108 & 45 & 42 & 15 & 14 \\
\hline
\end{tabular}


As a result of the collaborative study, oxygen use in premature infants was restricted. The concept that concentrations of oxygen under $40 \%$ were safe was not a finding of the collaborative study but, rather, was based on limited clinical findings. ${ }^{19}$ Incubators were redesigned with a red plastic flag on the back, which had to be raised in order to exceed $\sim 40 \%$ oxygen in the incubator. Following this restriction of oxygen use, there was an increase in the mortality rate of infants with hyaline membrane disease ${ }^{20}$ and an increase in cerebral palsy in premature infants. ${ }^{21}$ Fortunately, blood gas monitoring became generally available in the early $1960 \mathrm{~s}^{22}$ and was followed by the development of transcutaneous oxygen sensors and saturation monitors so that oxygen restriction was used more appropriately.

However, as the survival of smaller infants improved, the incidence of RLF continued to be significant in very small premature infants and was renamed retinopathy of prematurity (ROP) to indicate its relation to gestational age. The search for ROP's etiology continues.

\section{INITIAL THIRSTING/STARVING}

When I began pediatric training in 1957 at the University of Michigan, premature infants were not given intravenous fluids or enteral feedings for 72 hours. This peculiar approach became the norm in the US and England in the 1940s; it is well detailed in the book of Cone, ${ }^{23}$ History of the Care and Feeding of the Premature Infant (pp. 93-96), and in a review by Davies. ${ }^{24}$ Two influential pediatricians in Europe, Ylppö in Finland and Gleiss in Germany, consistently disagreed with this idea and advocated early breast milk feeding as had Budin ${ }^{8}$ at the turn of the century. Dr Clement Smith attributed this restricted feeding approach to Dr Stewart Clifford. Dr Smith justified this practice based on fear of aspiration by the small infant and the observation that many of these infants were edematous after birth and, therefore, must be fluid-overloaded. ${ }^{25}$ Another influential factor was the slow excretion of excess fluids in newborn infants as reported by Ames. ${ }^{26}$ Dr Smith, who had grown up and been educated in Ann Arbor, returned there for a month several summers while I was there and was my attending physician in the newborn nursery. As I respected him and his textbook, The Physiology of the Newborn Infant, ${ }^{27}$ first published in 1945, I never questioned this practice of withholding feeds and fluids. And the fear of aspiration was real. Each morning when we walked into the premature infant nursery, we expected to be disappointed by the unexpected death of a seemingly well infant. And these sudden deaths we attributed (probably erroneously) to aspiration because the infant usually had formula in the mouth when found. Dr Smith ultimately changed his attitude about feeding. In his 1962 Borden Award address, he explains the physiological studies that led to this change and stated, ". . . the therapeutic possibilities of earlier feeding become suddenly more attractive." ${ }^{28}$ By 1961, Usher ${ }^{29}$ was reporting a lowered mortality rate in small infants with respiratory distress who had begun intravenous glucose and bicarbonate infusions shortly after birth. This treatment was based on his finding of metabolic acidosis, hypoglycemia, and hyperpotassemia before death in small infants with respiratory distress. I remember being skeptical about this treatment method. I was probably reacting negatively to his zeal in promoting the treatment and to the limited data from a small controlled study. But he was correct and had a great influence on the development of appropriate therapy in neonatology. Also, in the mid 1960s, there were reports of the possible relation of delayed feedings to a higher incidence of neurological handicap and cerebral palsy. ${ }^{30,31}$ The clear advantage to earlier feeding was a decrease in hypoglycemia and hyperbilirubinemia along with a quicker regaining of birth weight. ${ }^{32}$ There were few controlled studies and even those studies showed conflicting results. ${ }^{33}$ Winick and Noble ${ }^{34}$ showed that the ultimate number of brain cells depended upon early nutritional adequacy in growing rats. His work had a large impact on promoting early feeding. Although opposition to early feeding remained, by 1970, this erroneous trend was generally discounted.

We cannot measure the effect of early thirsting and starving in those years on mortality and morbidity. I think the remarkable improvements in mortality over the last 50 years are mostly attributable to adequate nutrition, appropriate temperature control, antibiotics, and ventilation methods.

\section{SYNTHETIC VITAMIN K PROPHYLAXIS}

Hemorrhagic disease of the newborn was described by Townsend ${ }^{35}$ in 1894. The disease was characterized by bleeding at many locations: mouth, nose, skin, anus, umbilicus, and internal organs. The bleeding usually started in the first week of life. During subsequent years, various coagulation factors in blood were described and low prothrombin levels in newborn infant's blood were recognized. Kugelmass ${ }^{36}$ demonstrated the relation between prothrombin deficiency and hemorrhagic disease of the newborn in 1932. In 1939, Waddell and Guerry ${ }^{37}$ were two of several independent investigators showing the role of vitamin $\mathrm{K}$ in preventing hemorrhagic disease of the newborn. Drs. Waddell, Birdsong, and Lambdin (see section on chloramphenicol) were my professors of Pediatrics at the University of Virginia from 1953 to 1957. I remember the respect we had for Dr Waddell due to his participation in this discovery. The best historical review of these developments and the most conclusive proof of the relationship between vitamin $\mathrm{K}$ deficiency and bleeding in the newborn infant was presented by Dam et al. ${ }^{38}$ in 1952.

Vitamin K's discovery is attributed to the abovementioned Henrik Dam in 1929 at the University of Copenhagen. He recognized a hemorrhagic condition in chicks fed a fat-free diet. This condition was cured by administering an ether extract of alfalfa; this alfalfa extract was later shown to contain phylloquinone and the active ingredient was named vitamin $\mathrm{K}^{39}$

The deficiency of vitamin K occurred predominantly in breast-fed infants because the breast milk's vitamin $\mathrm{K}$ content is quite low. This deficiency led to decreased production of coagulation proteins by the liver, especially prothrombin. As treatment of this deficiency with 
vitamin $\mathrm{K}$ was successful, prophylaxis was begun at the time of birth. The prophylactic use of vitamin $\mathrm{K}$ in newborns began in the early 1940s and was the second routine pharmacological treatment of newborn infants; the first being the use of silver nitrate to prevent ophthalmia neonatorum begun by Credé in $1881{ }^{40}$ In 1954, the American Academy of Pediatrics recommended a dose of $5 \mathrm{mg}$ of synthetic vitamin $\mathrm{K}$ for all newborn infants. ${ }^{41}$

In 1955, Allison, ${ }^{42}$ in a short letter to The Lancet, mentioned his experience of seeing cases of hemolytic anemia, hyperbilirubinemia, and kernicterus in premature infants treated with large doses of synkavit, a water-soluble vitamin $\mathrm{K}$ analogue. Shortly thereafter, Laurance $^{43}$ reported an increased incidence of kernicterus after raising the dose of synkavit administered to premature infants from $10 \mathrm{mg}$ on admission to $10 \mathrm{mg}$ t.d.s. for 3 days. In an extensive article considering the causes of kernicterus in premature infants without isoimmunization, Crosse et al. ${ }^{44}$ identified large doses of vitamin $\mathrm{K}$ as a risk factor. She noted that it was then common practice to give daily doses of vitamin $\mathrm{K}$ to infants who had not started feeding. This practice resulted in many premature infants receiving cumulative doses above $50 \mathrm{mg}$. Table 4 illustrates the increase in cases of kernicterus between 1945 and 1964 as the routine dose of vitamin K increased.

The exact mechanism of the toxicity was never fully elucidated. A review of the studies on mechanism was presented by Dyggve ${ }^{45}$ in 1960. As he pointed out, there were previous reports of acute hemolysis in animal studies, especially in vitamin E-deficient rats. Also Heinz inclusion bodies were increased in premature infants receiving the drug. However, in his study of premature infants, although the bilirubin was increased (as in most studies of this kind), there was no clear evidence of hemolysis. In addition, he showed, like others before him, that vitamin $K_{1}$ (the natural form of the vitamin) did not cause hyperbilirubinemia.

In 1961, the American Academy of Pediatrics, Committee on Nutrition, ${ }^{46}$ reviewed the subject of hemorrhagic disease of the

\begin{tabular}{|ccccc|}
\hline Table & $\mathbf{4}$ & Kernicterus and Vitamin K Dosage & \multicolumn{2}{l|}{} \\
\hline Year & $\begin{array}{c}\text { Vitamin K } \\
\text { (total mg) }\end{array}$ & Admissions & \multicolumn{2}{c|}{ Kernicterus } \\
\cline { 3 - 5 } & & & Total & $\%$ \\
\hline 1945 & $1-2$ & 215 & 2 & 0.9 \\
1946 & $1-2$ & 234 & 5 & 2.1 \\
1947 & $1-2$ & 254 & 2 & 0.8 \\
1948 & $1-2$ & 219 & 1 & 0.5 \\
1949 & 10 & 243 & 4 & 1.6 \\
1950 & 30 & 252 & 3 & 1.2 \\
1951 & 30 & 269 & 3 & 1.1 \\
1962 & 30 & 263 & 1 & 0.4 \\
1963 & $30+$ & 316 & 13 & 4.1 \\
1964 & $30+$ & 334 & 12 & 3.6 \\
\hline Adapted from Ref. $[42]$. & & & \\
\hline
\end{tabular}

newborn and vitamin $\mathrm{K}$ treatment. They pointed out that the toxicity of vitamin $\mathrm{K}$ was associated with large doses of synthetic vitamin $\mathrm{K}$ analogues and recommended the prophylactic use of natural vitamin $\mathrm{K}_{1}, 0.5$ to $1.0 \mathrm{mg}$ parenterally.

I can find no publication that gave a rationale for or advocated the use of increased doses of vitamin K. Again, it is impossible to quantitate the damage done but, considering the broad use of large doses of synthetic vitamin K and the years of use (1945-1961), I believe it was extensive.

\section{SMA FORMULA CHANGE}

In December 1952, the FDA received a letter from a nurse in Arkansas whose 3-month-old infant had developed convulsions. The attending pediatrician apparently suspected that the condition was related to the formula, SMA liquid. The formula was changed to an evaporated milk formula and the child recovered. The mother heard of eight similar cases and that led to her letter. Upon further investigation, the FDA found that the manufacturer had heard of the problem and knew of 12 cases. $^{47}$

A description of the typical case is illustrated by the following case history from one of the first clinical articles. ${ }^{48}$ A 2 1/2-month-old infant was admitted to St. Joseph's hospital in Lancaster, PA, with staring episodes and generalized seizures. At 1 month of age, the infant had become irritable and had colic; the parents noticed also tossing of the head and stiffening of the body. In the hospital, the infant's electroencephalogram between seizures was normal as were all other laboratory tests. While in the hospital, the infant improved and the convulsions stopped. The baby was discharged and remained normal without medications. A detailed review of several additional cases showed only one common factor: the infants had all been fed liquid SMA formula and no solids. Once admitted to the hospital, the infants were fed an evaporated milk formula and cereal. The one infant fed liquid SMA and cereal in the hospital recovered but the convulsions returned when the cereal was stopped.

As SMA was the presumed culprit, the FDA began extensive investigations for toxic materials. None was found. The formula had recently been changed by replacing the coconut oil in the fat with palm oil. Also heat sterilization of the formula had been instituted. In an interesting review of this epidemic, May ${ }^{49}$ credits Dr Kline of the FDA with first suggesting that the convulsions might be related to vitamin $\mathrm{B}_{6}$ deficiency. Vitamin assays were performed and the level of vitamin $B_{6}$ was found to be quite low. Wyeth sent a general notice to all physicians describing this problem with their formula. A national survey revealed 300 cases of formula-induced vitamin $\mathrm{B}_{6}$ deficiency. ${ }^{50}$

The 1930s had seen great progress in the study of vitamins. In 1934, Gyorgy used the term $B_{6}$ to describe a substance in crude feed supplements that cured a florid dermatitis in rats fed purified feed with only vitamins $B_{1}$ and $B_{2}$ added. In 1938, five research groups purified crystalline $\mathrm{B}_{6}$; in 1939 , its chemical formula was elucidated and the name pyridoxine given. By 1942, the three forms of $B_{6}$ had 
been isolated. ${ }^{51}$ In 1950, Snyderman et al. ${ }^{52}$ first described convulsions in an infant on a $\mathrm{B}_{6}$-deficient diet.

This epidemic's deficiency resulted from a change in Wyeth's handling of the liquid formula. As a precaution against any possible contamination of the concentrated liquid product, a new sterilizing procedure, high-pressure autoclaving, was instituted, which reduced the $\mathrm{B}_{6}$ content of the milk from $\sim 210 \mu \mathrm{g} / 1$ in the raw formula to $60 \sim \mu \mathrm{g} / 1$ in the liquid concentrate. ${ }^{53}$ Interestingly, the cases involved in this epidemic were useful in establishing the $\mathrm{B}_{6}$ requirement of infants. ${ }^{54}$

\section{DIAPER MARKINGS}

As in a Dickens novel, an article in the February 13, 1886 British Medical Journal begins, "Early one morning, in July last, the night nurse of the Marylebone Workhouse, on going around the lying-in ward, noticed that one of the infants looked, as she said, "very blue and queer.' The mother, with whom the child (a week old) was sleeping, was fast asleep, and the nurse thought the child must have been overlaid; but as the lividity remained, I was sent for."

Dr Rayner, the author of this article, then looked around and found four other children with this strange "wimberry" (grape) color. On this occasion, 10 infants were affected and no cause was found. The following December, seven more infants appeared with this peculiar blue-gray cyanosis. When questioned carefully, the midwife remembered that on both occasions, a "fresh supply of napkins" had arrived and been used. On examining one of the infants, Dr Rayner noted dye on the buttocks, with the same pattern used to mark the diapers (as property of the workhouse). The dye was found to be chloride of aniline and the epidemic disappeared after the diapers were washed. Dr Rayner reproduced this problem in another newborn, "A freshly stamped napkin was used for a strong healthy infant, and this became cyanosed in less than twenty-four hours." In those days, the attitude toward experimentation was somewhat different.

This error is a good example of history repeating itself. Graubarth et al. ${ }^{56}$ in 1945 updated us on other instances of cyanosis secondary to aniline marking on diapers and reported their experience with another 17 infants. Cases have also been reported from marked wash cloths used on babies. ${ }^{57}$

In an epidemic reported by Fisch et al. ${ }^{58}$ in 1963, 18 cases of methemoglobinemia occurred and were thought to be due to trichlorocarbanilide used in the laundering process of clothing, diapers, and linens. This article well describes the difficulty in determining precisely the toxic compound.

Many chemicals can cause methemoglobinemia. The mechanism of action is the oxidation of the iron in hemoglobin, ferrohemoglobin to ferrihemoglobin (methemoglobin), which decreases its ability to release oxygen. And although this oxidation occurs normally at about $3 \%$ per day, there are enzymes (especially $\mathrm{NADH}$ methemoglobin reductase) in the erythrocyte that normally reduce the iron back to ferrohemoglobin. In the newborn infant, these enzymes are less active and so the baby is more sensitive to the effect of oxidizing drugs. ${ }^{59}$

In 1989, cases of methemoglobinemia were noted in premature infants at a neonatal intensive care unit (NICU) in Copenhagen. ${ }^{60}$ The doctors began a careful prospective study of the methemoglobin levels in all the patients on the unit and gathered epidemiological data. This study was carried out for 8 months and no clear cause of the methemoglobinemia was found. Some months later, they realized that chlorhexidine solution was being added to the humidifying solution of their new incubators. This antiseptic had been used for a long time with their older incubators, but new incubators had been put into use just before the epidemic began. The older incubators heated the humidifying solution to about $20^{\circ} \mathrm{C}$, but the new incubators heated the solution to $100{ }^{\circ} \mathrm{C}$. Chlorhexidine raised to this temperature decomposes to para-chloraniline, which is known to cause methemoglobinemia. A statistically significant relationship was found between length of exposure in the new incubators and elevated methemoglobin levels. After the removal of chlorhexidine, there were no more methemoglobin-positive babies.

\section{Acknowledgements}

The author is grateful for the helpful comments and suggestions of W.A. Silverman and Jeffrey P. Baker, and for the extensive grammatical review by Alex F. Robertson IV.

\section{References}

1. Silverman WA. Retrolental Fibroplasia: A Modern Parable. New York: Grune and Stratton; 1980.

2. Roueché B. Three sick babies. In:. Medical Detectives. New York: Truman Talley Books/Plume; 1988. p. 200-16.

3. Silverman WA. Neonatal pediatrics at the century mark. Perspect Biol Med 1989;32:159-69.

4. Baker JP. The Machine in the Nursery. Baltimore: Johns Hopkins University Press; 1996.

5. Cone TE. The first published report of an incubator for use in the care of the premature infant (1857). Am J Dis Child 1981;135:658-60.

6. Baker JP. The incubator and the medical discovery of the premature infant. J Perinatol 2000;5:321-8.

7. Hess JH. Premature and Congenitally Diseased Infants. Philadelphia: Lea and Febiger; 1922

8. Budin P. The Nursling. Edinburgh: Caxton Publishing; 1907, translated by WJ Maloney.

9. Blackfan KD, Yaglou CP. The premature infant: a study of the effects of atmospheric conditions on growth and development. Am J Dis Child 1933; $46: 1175-236$

10. Silverman WA. The future of clinical experimentation in neonatal medicine. Pediatrics 1994;94:932-8.

11. Silverman WA. The physical environment and the premature infant. Pediatrics 1959;23:166-71.

12. Martin L. Oxygen Therapy: The First 150 Years 1999. www.mtsinai.org/ pulmonary/papers/ox-hist/ox-hist-intro.html

13. Bakwin H. Oxygen therapy in premature infants with anoxemia. Am J Dis Child 1923;25:157-62. 
14. Hess JH. Oxygen unit for premature and very young infants. Am J Dis Child 1934;47:916-7.

15. Chapple CC. Controlling the external environment of premature infants in an incubator. Am J Dis Child 1938;50:459-60.

16. Wilson JL, Long SB, Howard PJ. Respiration of premature infants: response to variations of oxygen and to increased carbon dioxide in inspired air. Am J Dis Child 1942;63:1080-5.

17. Smith CA. The continued use of oxygen for premature infants. Bull NY Acad Med 1950;26:430-3.

18. Silverman WA. "Collateral damage" in perinatal warfare. Paediatr Perinat Epidemiol 2002;16:98-9.

19. Lanman JT, Guy LP, Dancis J. Retrolental fibroplasia and oxygen therapy. JAMA 2002;155:223-6.

20. Avery ME, Oppenheimer EH. Recent increase in mortality from hyaline membrane disease. J Pediatr 1960;57:553-9.

21. McDonald AD. Cerebral palsy in children of very low birth weight. Arch Dis Child 1963;38:579-88.

22. Snider GL. Historical perspective on mechanical ventilation: from simple life support system to ethical dilemma. Am Rev Respir Dis 1989;140:52-7.

23. Cone TE. History of the Care and Feeding of the Premature Infant. Boston: Little, Brown and Co.; 1985.

24. Davies DP. The first feed of low birthweight babies: changing attitudes in the twentieth century. Arch Dis Child 1978;53:187-92.

25. Smith CA, Yudkin S, Young W, Minkowski A, Cushman M. Adjustment of electrolytes and water following premature birth. Pediatrics 1949;3:34-48.

26. Ames RG. Urinary water excretion and neurohypophyseal function in full term and premature infants shortly after birth. Pediatrics 1953;12:27282.

27. Smith CA. The Physiology of the Newborn Infant. Springfield: Charles C. Thomas; 1945.

28. Smith CA. Prenatal and neonatal nutrition: Borden Award address. Pediatrics 1962;30:145-56.

29. Usher R. The metabolic changes in respiratory distress syndrome of prematurity seen as a failure of somatic compensations for asphyxia. In: Ciba Foundation Symposium on Somatic Stability in the Newly Born. London: Churchill; 1961. p. 92-116.

30. Drillien CM. The Growth and Development of the Prematurely Born Infant. Edinburgh: Livingstone; 1964. p. 302-8.

31. Churchill JA. Weight loss in premature infants developing spastic diplegia. Obstet Gynecol 1963;22:601-5.

32. Smallpiece V, Davies PA. Immediate feeding of premature infants with undiluted breast-milk. Lancet 1964;2:1349-52.

33. Cornblath M, Forbes AE, Pildes RS, Luebben G, Greengard J. A controlled study of early fluid administration on survival of low birth weight infants. Pediatrics 1966;38:547-54.

34. Winick M, Noble A. Quantitative changes in DNA, RNA, and protein during prenatal and postnatal growth in the rat. Dev Biol 1965;12:451-66.

35. Townsend CW. The hemorrhagic disease of the newborn. Arch Pediatr 1894;II:559-65.

36. Kugelmass $\mathrm{N}$. The management of hemorrhagic problems in infancy and childhood. JAMA 1932;99:895-902.

37. Waddell WW, Guerry D. Effect of vitamin $\mathrm{K}$ on the clotting time of the prothrombin and the blood: with special reference to unnatural bleeding of the newly born. JAMA 1939;112:2259-63.

38. Dam H, Dyggve H, Larsen H, Plum P. The relation of vitamin K deficiency to hemorrhagic disease of the newborn. Adv Pediatr 1952;5:129-53.

39. Greer FR. Special needs and dangers of fat-soluble vitamins A, E and K. In: Tsang RC, Zlotkin SH, Nichols BL, Hansen JW, editors. Nutrition During Infancy; Principles and Practice, 2nd ed. Cincinnati: Digital Educational Publishing; 1997. p. 286.

40. Speert H. Carl Siegmund Franz Credé, placental expression, and the prevention of neonatal ophthalmia. Obstet Gynecol 1957;10:335-9.

41. Committee on Fetus and Newborn. Standards and Recommendations for Hospital Care of Newborn Infants, 2nd ed. Evanston: American Academy of Pediatrics; 1954.

42. Allison AC. Danger of vitamin K to newborn. Lancet 1955;I:669.

43. Laurance B. Danger of vitamin-K analogues to newborn. Lancet 1955;1: 819.

44. Crosse VM, Meyer TC, Gerrard JW. Kernicterus and prematurity. Arch Dis Child 1959;30:501-8.

45. Dyggve H. Bilirubin studies in premature infants who received menadione derivatives or vitamin K1 at birth. Acta Paediatr 1960;49:230-42.

46. Committee on Nutrition. Vitamin $\mathrm{K}$ compounds and the water-soluble analogues: use in therapy and prophylaxis in pediatrics. Pediatrics 1961;28:501-7.

47. Nelson EM. Association of vitamin B6 deficiency with convulsions in infants. Public Health Rep 1956;71:445-8.

48. Coursin DB. Convulsive seizures in infants with pyridoxine-deficient diet. JAMA 1954;154:406-8.

49. May $\mathrm{CD}$. Vitamin $\mathrm{B}_{6}$ in human nutrition: a critique and an object lesson. Pediatrics 1954;14:269-79.

50. Coursin DB. Vitamin $\mathrm{B}_{6}$ deficiency in infants: a follow-up study. Am J Dis Child 1955;90:344-8.

51. Leklem JE. Vitamin $B_{6}$. In: Machlin LJ, editor. Handbook of Vitamins, 2nd ed. New York: Marcel Dekker; 1991. p. 342-78.

52. Snyderman SE, Holt LE, Carretero R, Jacobs K. Pyridoxine deficiency in the human infant. J Clin Nutr 1953;1:200-7.

53. Coursin DB. Symposium on frontiers in nutrition in relation to milk; vitamin B6 (pyridoxine) in milk. Q Rev Pediatr 1955;10:1-9.

54. Bessey $\mathrm{OA}$, Adam DJ, Hansen $\mathrm{AE}$. Intake of vitamin $\mathrm{B}_{6}$ and infantile convulsions: a first approximation of requirements of pyridoxine in infants. Pediatrics 1957;20:33-44.

55. Rayner W. Cyanosis in newly born children caused by aniline marking ink. Br Med J 1886;1:294.

56. Graubarth J, Bloom CJ, Coleman FC, Soloman H. Dye poisoning in the nursery: a review of seventeen cases. JAMA 1945;128:1155-7.

57. Scott EP, Prince GE, Rotondo CC. Dye poisoning in infancy. J Pediatr 1946;28:713-8.

58. Fisch R0, Berglund EB, Bridge AG, Finley PR, Quie PG, Raile R. Methemoglobinemia in a hospital nursery. JAMA 1963;185:760-3.

59. Herzog P, Feig SA. Methaemoglobinaemia in the newborn infant. Clin Haematol 1978;7:75-83.

60. Hjelt K, Lund JT, Scherling B, et al. Methaemoglobinaemia among neonates in a neonatal intensive care unit. Acta Pediatr 1995;84:365-70. 